
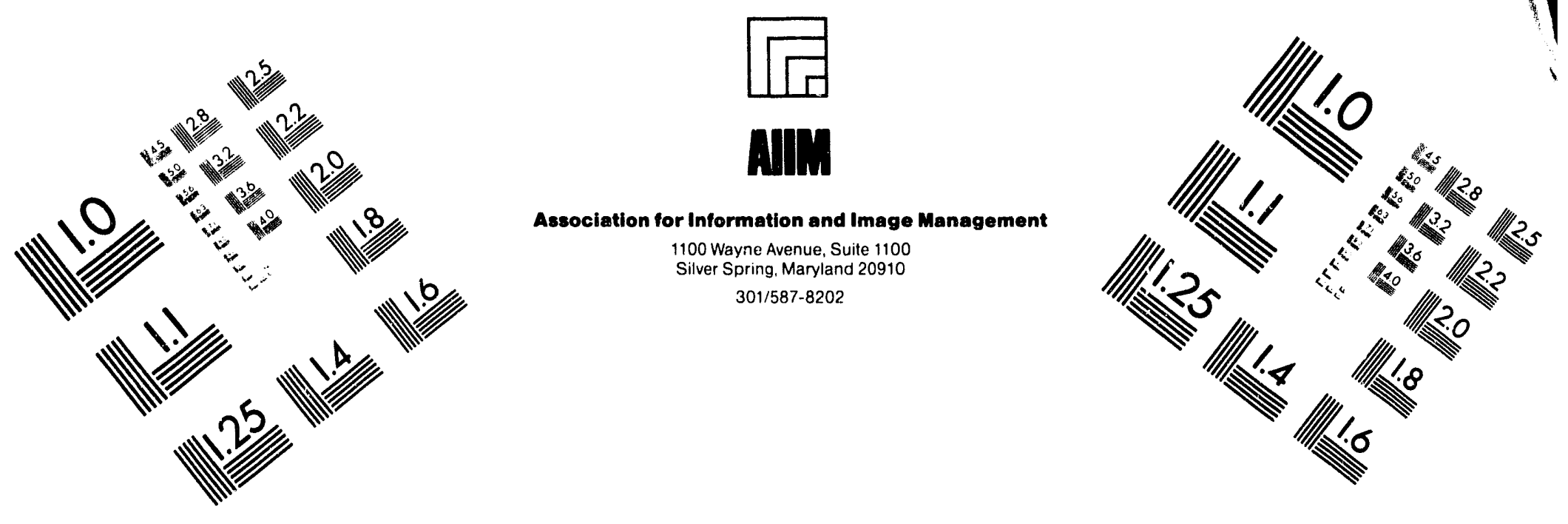

\title{
Centimeter
}

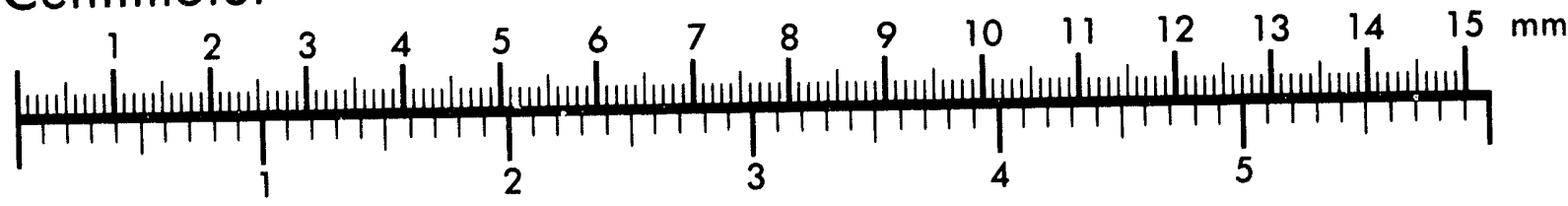
Inches
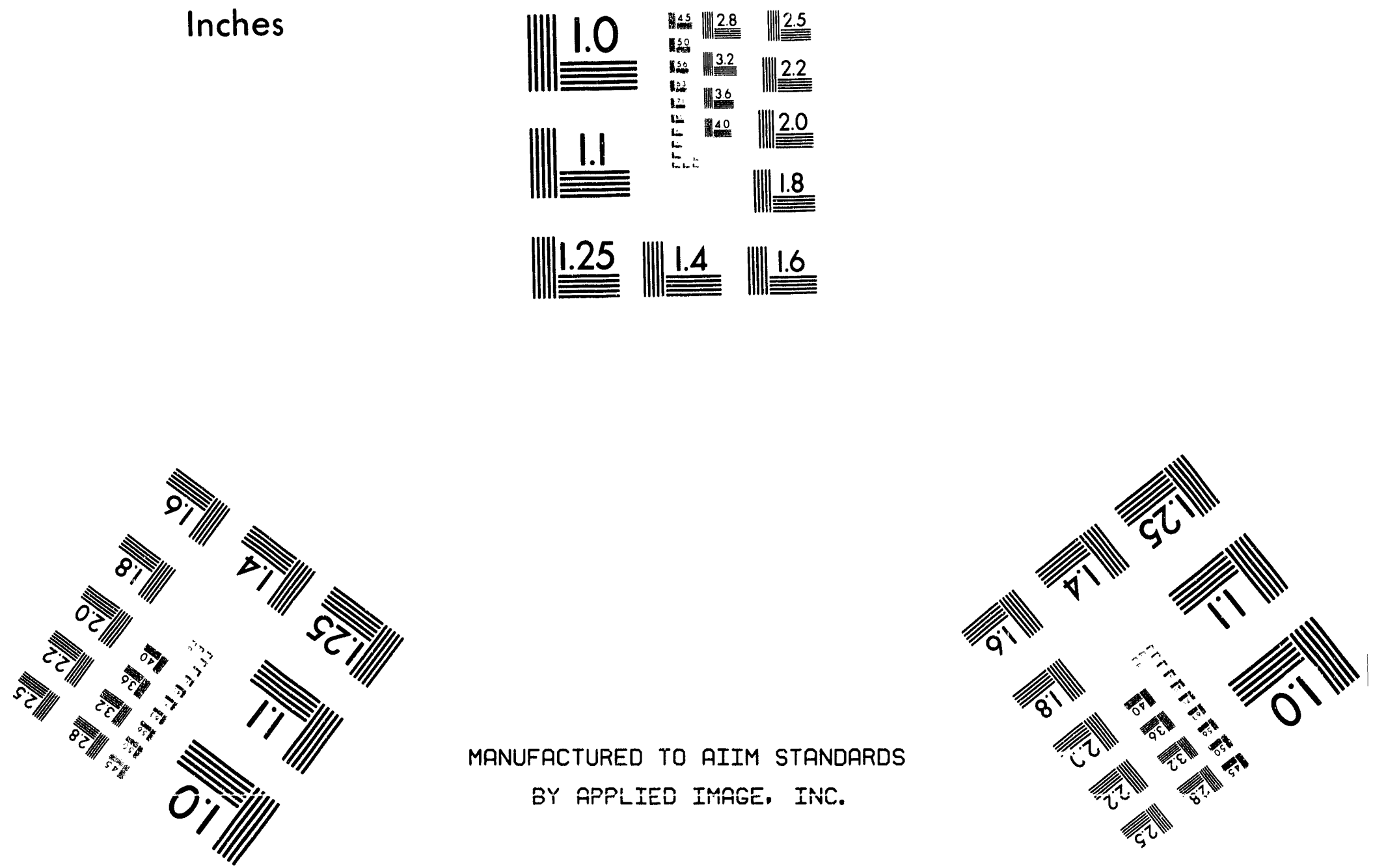

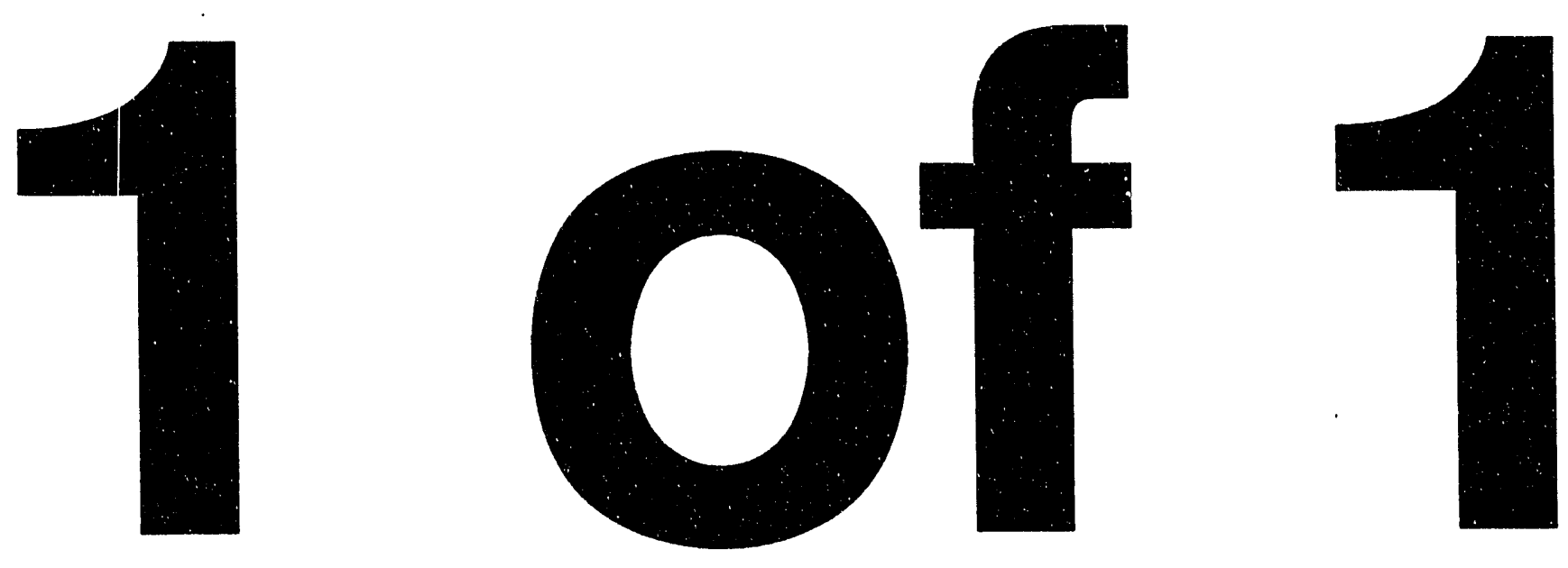
QUARTERLY PROGRESS REPORT

ON

\section{CONFIGURATIONAL DIFFUSION OF \\ ASPHALTENES IN FRESH AND \\ AGED CATALYSTS EXTRUDATES}

MAY 251990

Grant No. DE-FG22-91PC91311

$12-20-92$ to $3-20-93$

James A. Guin

A Ray Tarrer

Chemical Engineering Department

Auburn University

Auburn, AL 36849

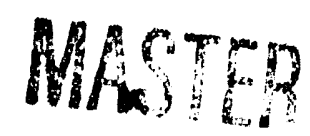


Table of Contents

Objective and Work Statement-1

Summary of Progress

Planned Work

Detailed Progress---Influence of External Mass Transfer In Diffusion

Experiment

Estimates of Concentration and Mass Transfer Coefficient from

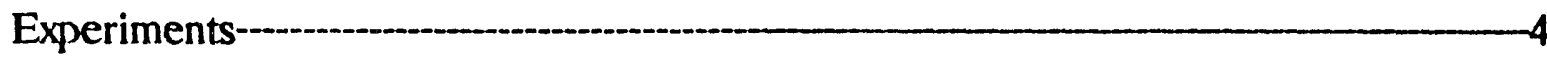

Mass Transfer into Particles-

External Mass Transfer-_-_-5

Comparison of External Mass Transfer Rate with Flux into Particles--------6

Theoretical Analysis of External Mass Transfer Effect-1-8

Actual Experiments with Different Particle Sizes-11

Stirring Speed Experiments-_-12

Comparison of Diffusion Results in Metal and Glass Cells-a-13

Conclusions--13 13 


\section{Statument of Work \\ Configurational Diffusion of Asphaltenes in Fresh and Aged Porous \\ Catalyst Extrudates}

Objective: The objective of this research is to determine the relationship between the size and shape of coal and petroleum macromolecules and their diffusion rates i.e., effective diffusivities, in catalyst pore structures. That is, how do the effective intrapore diffusivities depend on molecule configuration and pore geometry.

Task 1. Relationship Between Effective Intrapore Diffusion Coefficients, Molecular Size and Pore Geometry.

Finite bath-type diffusion experiments will be performed using both coal and petroleum-derived macromolecular species, e.g. asphaltenes, as well as model compounds, e.g. porphyrins, polymers, of known molecular size. By monitoring the concentration of solute macromolecules in the bath, the effective intrapore diffusion coefficients will be determined through application of the appropriate diffusion equations. Macromolecular species concentrations will be monitored by size exclusion chromatography (SEC). Relationships will be sought between the size, and shape, e.g. planar, coil, of the diffusing solutes and the pore geometry (pore size distribution) of the catalyst support. The effects of molecule configuration and catalyst pore size distribution on the effective intrapore diffusivity will be examined. Specially prepared laboratory catalysts with very narrow pore size distributions and other model porous media, e.g. porous Vycor glass, will be utilized in the experiments. Pore structures of all catalysts and other porous media will be characterized by mercury porosimetry and surface area (BET) analysis.

Task 2. Effects of Solvent Composition, Solute Concentration, and Temperature on the Molecular Configuration and Diffusion Rate of Coal and Petroleum Asphaltenes in Catalyst Pores. 
Diffusion experiments such as in Task 1 will be performed with varying solvent compositions, i.e., paraffinic-aromatic mixtures, to examine the effects of the state of molecular aggregation (self-assemblies) on the rates of diffusion of coal and petroleum asphaltenes in the catalyst pores. Similar experiments will be performed to study the effect of temperature and solute (macromolecule) concentration on the state of molecular configuration and aggregation on the resulting pore diffusivity.

\section{Task 3. Assessment of Diffusional Limitations in Aged Catalysts}

Diffusivity measurements such as conducted in Task 1 will be performed with both model compound and coal-derived macromolecular species using extrudate-type aged catalysts from laboratory experiments as well as aged catalysts obtained from actual coal liquefaction pilot plants such as the Wilsonville, AL Advanced Coal Liquefaction R \& D Facility. From the experimental diffusivities so obtained, an evaluation of effects of changes in catalyst pore structure, e.g. tortuosity, pore plugging, shall be made. The changes in pore diffusivities associated with the pore structural changes caused by coke and metals deposition will be investigated, as compared with the fresh catalysts. As assessment of the relationship of increased diffusional limitations to coke and metals deposition in the catalyst pores will be made based on the results of the diffusivity measurements. The degree to which pore diffusivities can be restored to their original values by carefully controlled oxidation and/or extractive catalyst regeneration techniques also will be explored. The practical importance of these findings to coal liquefaction technology will be evaluated. 


\section{Summary}

This quarter, we took several approaches to check the effect of external mass transfer on the diffusion rate. Theoretical analyses and experimental results showed that the external mass transfer effect can be neglected for our experimental conditions.

\section{Planned Work}

Next quarter we will use fresh as well as aged catalysts in the diffusion system. The effect of catalyst aging on the diffusion kinetics will be surveyed. Also, additional diffusional systems will be employed, possibly using TPP as a diffusional solute. Experimental work will include both diffusional uptake and equilibrium adsorption experiments. 
Consider a porous particle immersed in a stirred finite bath containing solute and solvent. The solute molecules are diffusing into the porous particle. The mathematical diffusion model can be set up based on certain assumptions. If there is an external mass transfer influence, the mathematical model set up and the model solution include the existence of the external mass transfer term.

As discussed before, for a specific diffusion system with negligible external mass transfer effect, a simplified mathematical diffusional model has been obtained. To insure that the external mass transfer is negligible and can be eliminated, the following theoretical and experimental work has been performed.

\section{ESTIMATES OF BURFACE CONCENTRATION AND MASS TRANSFER COEFFICIENT FROY BXPERIMENTS}

The external mass transfer effect can be estimated from the values of the external mass transfer coefficient $k_{c}$ and the particle surface concentration as follows.

\section{Mass Transfer into Particles}

The mass transfer flux into the particles can be expressed as

$$
N_{A p} 4 \pi R^{2} n_{p}=-V_{b} \frac{d C_{b}}{d t}
$$

or 


$$
N_{A p}=-\frac{R}{3} \frac{V_{b} \rho_{p}}{W} \frac{d \theta_{b}}{d t} C_{b 0}
$$

In the above equation, the derivative of $\theta_{b}$ with respect to $t$ can be obtained from experiments. The other parameters for a given diffusion system are also known. For the diffusion of quinoline in cyclohexane with shell 324 catalyst, the parameters are:

$$
\rho_{p}=1.4 \mathrm{~g} / \mathrm{Cc}, \mathrm{V}_{\mathrm{b}}=195 \mathrm{cc}, \mathrm{W}=0.2 \mathrm{~g} \text {, }
$$

Thus the flux into the particle can be obtained.

External Mass Transfer

The external mass transfer flux can be expressed as

$$
N_{A E}=k_{c}\left(C_{b}-\left.C_{s}\right|_{r=R}\right)
$$

where $k_{c}$ can be estimated by the empirical equation(Bird, "Transport Phenomena", eq. 21.2-25, p647)

$$
\left(\frac{k_{c} D_{p}}{D_{A B}}\right)=2+0.6\left(\frac{\rho u_{\infty} D_{p}}{\mu}\right)^{\frac{1}{2}}\left(\frac{\mu}{\rho D_{A B}}\right)^{\frac{1}{3}}
$$

or

$$
k_{c}=\frac{D_{A B}}{D_{P}}\left[2+0.6\left(\frac{\rho u_{\infty} D_{P}}{\mu}\right)^{\frac{1}{2}}\left(\frac{\mu}{\rho D_{A B}}\right)^{\frac{1}{3}}\right]
$$

The values for other parameters in above equation for a specific diffusion system can be estimated. For the diffusion of quinoline in cyclohexane with shell 324 catalyst in the mechanically stirred metal cell:

$$
\mu=0.65 \mathrm{cp}=0.0065 \mathrm{~g} / \mathrm{cm} . \mathrm{s}
$$




$$
\begin{aligned}
& D_{A B}=1 * 10^{-5} \mathrm{~cm}^{2} / \mathrm{s} \\
& \rho=0.7 \mathrm{~g} / \mathrm{cC} \\
& u_{\Delta}=r_{B} \omega=2 * 2 * 800 * \pi / 60=168 \mathrm{~cm} / \mathrm{s}
\end{aligned}
$$

where $r_{B}$ is the radius of the rotating basket, and $\omega$ is the angular speed of the rotating basket containing the catalyst particles.

\begin{tabular}{|c|c|c|c|}
\hline $\begin{array}{l}D_{p}, c m \\
0.16 \\
0.10 \\
0.08 \\
0.04\end{array}$ & $\begin{array}{l}\text { Re } \\
2895 \\
1809 \\
1447 \\
724\end{array}$ & $\begin{array}{l}\text { Sc } \\
930 \\
930 \\
930 \\
930\end{array}$ & $\begin{array}{r}\mathrm{k}_{\mathrm{c}}, \mathrm{cm} / \mathrm{s} \\
0.020 \\
0.025 \\
0.028 \\
0.040\end{array}$ \\
\hline
\end{tabular}

For different particle sizes, the estimated values for $k_{c}$ are listed in Table 1.

Comparison of External Mass Transfer Rate with Flux into Particles According to a material balance, the mass transfer into particle should be equal to the external mass transfer:

$$
N_{A P}=N_{A E}
$$

or

$$
-\frac{R}{3} \frac{V_{b} \rho_{p}}{W} \frac{d \theta_{b}}{d t} C_{b 0}=k_{c}\left(C_{b}-C_{s}\right)
$$

thus

$$
\theta_{b}-\theta_{s}=-\frac{R}{3 k_{c}} \frac{V_{b} \rho_{p}}{W} \frac{d \theta_{b}}{d t}
$$

The difference between dimensionless bath concentration and dimensionless surface concentration, $\theta_{b}-\theta_{s}$, can be estimated 
according to equation ( 8 ). The relative difference for these two values, $\left(\theta_{b}-\theta_{s}\right) / \theta_{b}$, can also be calculated. Table 2 lists the estimated values of $\left(\theta_{b}-\theta_{s}\right)$ and $\left(\theta_{b}-\theta_{s}\right) / \theta_{b}$ for different particle sizes. From this table it can be seen that the difference between $\theta_{b}$ and $\theta_{s}$ and the relative difference $\left(\theta_{b}-\theta_{s}\right) / \theta_{b}$ are very small, particularly at longer diffusion time. These results show that the resistance for the external mass transfer can be neglected.

Table 2. Estimated Surface Concentration and Sherwood Number

\begin{tabular}{|c|c|c|c|c|c|c|}
\hline & $\stackrel{t}{\min }$ & $\theta_{b}$ & $\begin{array}{c}d \theta_{\mathrm{p}} / \mathrm{dt} \\
* 10^{\mathrm{p}}, 1 / \mathrm{s}\end{array}$ & $\theta_{s}$ & $\theta_{b}-\theta_{s}$ & $\left(\theta_{b}-\theta_{s}\right) / \theta_{f}$ \\
\hline $\begin{array}{l}R=0.08 \mathrm{~cm} \\
k C=0.020 \\
S h p=1067\end{array}$ & $\begin{array}{r}30 \\
60 \\
120 \\
180 \\
310 \\
540 \\
720 \\
1380\end{array}$ & $\begin{array}{l}.923 \\
.863 \\
.790 \\
.747 \\
.684 \\
.610 \\
.568 \\
.479\end{array}$ & $\begin{array}{l}4.30 \\
3.22 \\
2.03 \\
1.17 \\
0.81 \\
0.54 \\
0.39 \\
0.23\end{array}$ & $\begin{array}{l}.844 \\
.802 \\
.753 \\
.726 \\
.669 \\
.600 \\
.561 \\
.477\end{array}$ & $\begin{array}{l}.078 \\
.060 \\
.037 \\
.021 \\
.015 \\
.010 \\
.007 \\
.002\end{array}$ & $\begin{array}{l}2.5 \\
\gamma .0 \\
4.7 \\
2.9 \\
2.2 \\
1.6 \\
1.2 \\
0.5\end{array}$ \\
\hline $\begin{array}{l}\mathrm{R}=0.055 \mathrm{~cm} \\
\mathrm{kc}=0.025 \\
\mathrm{Shp}=917\end{array}$ & $\begin{array}{r}30 \\
60 \\
120 \\
240 \\
458 \\
693 \\
1320\end{array}$ & $\begin{array}{l}.810 \\
.740 \\
.655 \\
.550 \\
.490 \\
.433 \\
.370\end{array}$ & $\begin{array}{r}10.55 \\
3.89 \\
2.36 \\
1.46 \\
0.46 \\
0.40 \\
0.17\end{array}$ & $\begin{array}{l}.705 \\
.701 \\
.632 \\
.536 \\
.485 \\
.429 \\
.368\end{array}$ & $\begin{array}{l}.105 \\
.039 \\
.023 \\
.014 \\
.005 \\
.004 \\
.002\end{array}$ & $\begin{array}{r}12.9 \\
5.2 \\
3.6 \\
2.6 \\
0.9 \\
0.9 \\
0.4\end{array}$ \\
\hline $\begin{array}{l}\mathrm{R}=0.039 \mathrm{~cm} \\
\mathrm{kc}=0.028 \\
\mathrm{Shp}=728\end{array}$ & $\begin{array}{r}30 \\
60 \\
120 \\
180 \\
300 \\
601\end{array}$ & $\begin{array}{l}.763 \\
.681 \\
.570 \\
.530 \\
.465 \\
.380\end{array}$ & $\begin{array}{r}13.17 \\
4.56 \\
3.08 \\
1.11 \\
0.90 \\
0.47\end{array}$ & $\begin{array}{l}.680 \\
.652 \\
.550 \\
.523 \\
.459 \\
.377\end{array}$ & $\begin{array}{l}.083 \\
.029 \\
.020 \\
.007 \\
.006 \\
.003\end{array}$ & $\begin{array}{r}10.9 \\
4.2 \\
3.4 \\
1.3 \\
1.2 \\
0.8\end{array}$ \\
\hline $\begin{array}{l}\mathrm{R}=0.018 \mathrm{~cm} \\
\mathrm{kC}=0.040 \\
\mathrm{Shp}=480\end{array}$ & $\begin{array}{r}10 \\
30 \\
60 \\
90 \\
120\end{array}$ & $\begin{array}{l}.741 \\
.620 \\
.481 \\
.420 \\
.382\end{array}$ & $\begin{array}{r}43.17 \\
10.08 \\
7.72 \\
3.39 \\
2.11\end{array}$ & $\begin{array}{l}.652 \\
.599 \\
.465 \\
.413 \\
.378\end{array}$ & $\begin{array}{l}.089 \\
.021 \\
.016 \\
.007 \\
.004\end{array}$ & $\begin{array}{r}12.0 \\
3.4 \\
3.3 \\
1.7 \\
1.1\end{array}$ \\
\hline
\end{tabular}


Table 2 also listed a modified sherwood number which was calculated by the formula:

$$
S h_{p}=\frac{2 R k_{c}}{D_{e}}
$$

Nerethieks(Nerethieks, I, "Adsorption in Finite Bath and Countercurrent Flow with system Having a Non-linear Isotherm", Chem. Eng. Sci., 31, 107(1976)) has shown that for adsorptive pore diffusion with the Freundich isotherm in a finite bath, the influence of the external mass transfer resistance is very small for $S h_{p}$ greater than 50. Crank's results (J. Crank, "The Mathematics of Diffusion, p92) showed that for a non-adsorption system, if $\mathrm{Sh}_{\mathrm{p}}$ is greater than 40 , the mass transfer effect can be neglected. As shown in Table 2, the values of sherwood number in our experiments are all greater than 480. Thus, it can also be concluded from these calculations that the external mass transfer effects in our diffusion runs are negligible.

\section{THEORETICAL ANALYSIS OF EXTERNAL MASS TRANSFER EFFECT}

For a diffusion system, if there is an external mass transfer resistance, the mass transfer flux from bulk solution to the particle is:

$$
N_{A}=-\left.D_{e} \frac{\partial C_{a}}{\partial r}\right|_{r=R}=k_{c}\left(C_{b}-C_{s}\right)
$$

Suppose a nor-adsorption process holds, then the fractional uptake will have the following form(J. Crank, "The Mathematics of 
Diffusion, p91)

$$
\frac{M_{t}}{M_{\infty}}=1-\sum_{n=1}^{\infty} \frac{6 L^{2} \exp \left(-\beta_{n}{ }^{2} t^{*}\right)}{\beta_{n}{ }^{2}\left(\beta_{n}{ }^{2}+L(L-1)\right)}
$$

where, $\beta_{n}$ 's are the roots of

$$
\beta_{n} \cot \left(\beta_{n}\right)+L-1=0
$$

and a Sherwood number $L$ is given by:

$$
L=\frac{R k_{c}}{D_{A B}}
$$

According to equation(5), for large values of the Reynolds number, the mass transfer coefficient $k_{c}$ is inversely proportional to the square root of the particle size. Suppose a series of experiments were performed with different size particles. In this case, for a particular solvent/solute/catalyst diffusion system, the differences in $L$ values are caused only by different particle sizes, then:

$$
L=C R^{0.5}
$$

where $C$ is a constant.

If there is no external mass transfer influence, or in equation (11), I approaches infinity, the solution can be simplified as:

$$
\frac{M_{t}}{M_{-}}=1-\sum_{n=1}^{\infty} \frac{6}{\beta_{n}^{2}} \exp \left(-\beta_{n}{ }^{2} t^{n}\right)
$$

Suppose an experiment with "infinite" $L$ value is performed in 
which $M_{t} / M_{b}$ is determined at different times, $t$. The values of $t^{*}$ corresponding to these experimental $M_{t} / M_{t}$ values can be found from equation (15). From the definition of $t^{*}$

$$
t^{*}=\frac{D_{A B}}{R^{2}} t
$$

we see that a plot of $t$ vs. $t$ will be linear through the origin. The question to be answered now is that if an experiment were performed in which there was significant mass transfer control, say, $I=0.1$, would a plot of $t$ calculated from equation(15) vs. $t$ still be linear. To answer this question we took several hypothetical $M_{\mathbb{V}} / M_{6}$ values and computed the corresponding $t$ values from equation (11) with $L=0.1$. This gave us a set of hypothetical "experimental" data with mass transfer control present. We then used the values of $t^{*}$ calculated from equation (15) to plot vs. $t$. The result is shown in Figure 1 , where it is observed that the data do not fit a straight line through the origin. Figures $2-5$ show similar analyses for various degrees of mass transfer control (various $I$ values). As $I$ becomes larger, the degree of mass transfer control diminishes and the data more closely fit a straight line through the origin.

Thus it can be concluded that if mass transfer is influencing the $M_{q} / M_{6}$ data, a plot of $t^{*}$ (from eqn. 15) vs. $t$ will not be linear, and the presence of external mass transfer will be thereby detected. Conversely, if such a plot is a straight line through origin, the external mass transfer effects are absent. 
Even though the plots in Figures $2-5$ are not linear, if a $t^{*}$ vs. $t$ plot is forced to be a straight line through the data, a "slope" can be obtained. This "slope" should be proportional to $\mathrm{R}^{-2}$ in the absence of mass transfer. The values of $R$ corresponding to the values of $L$ in Figures 2-5 can be found from eqn. (14). Then a log-log plot of the slopes from Figures 2-5 vs. the corresponding $R$ can be made as shown in Figure 6 . It is observed that the slope of this curve is not equal to -2 as it should be in the absence of mass transfer. However, as the particle size(and sherwood number) increases, or the external mass transfer control decreases, the slope does approach -2 .

Thus, if mass transfer is present and experiments are performed with several particle sizes, a plot such as in Figure 6 will not have a -2 slope. Conversely, if such a plot does have a -2 slope, we can conclude that external mass transfer effects are absent.

\section{ACTOAL EXPERIXENTS WITH DIFFERENT PARTICLE BIZES}

Based on the above theoretical analysis, diffusion runs with different particle sizes were performed to check the effect of external mass transfer. The diffusion system was the diffusion of quinoline in cyclohexane with fresh shell 324 catalyst. Results of the diffusion data for four particle sizes are shown in Figure 7 . Figure 8 plots $t$ vs. $t$ for different particle sizes. It can be seen that all the plots are straight lines, and the slopes of these lines are also shown in this Figure. The plot of logarithm of these 
slopes vs. logarithm of the particle sizes is shown in Figure 9, the slope of which is about -2 . According to the theoretical analysis above, all these results clearly show that external mass transfer effects are negligible.

Figure 10 and 11 also plot the dimensionless bath concentration $c_{b} / C_{b o}$ and $t^{*}$ vs. $t / R^{2}$, respectively. For four different particle sizes, $c_{b} / C_{b o} v s . t / R^{2}$ all lie on the same curve, and $t^{*} \mathrm{vs} . t / R^{2}$ is a straight line. These results are additional verifications of negligible external mass transfer effects.

\section{BTIRRING BPEED EXPERIMENTS}

stirring speed experiments were carried out in an mechanically agitated metal vessel to check the effect of external mass transfer. A basket for catalyst containment is connected to a motor through a Teflon bar. The stirring speed is controlled by a speed controller.

As we know, the external mass transfer can be minimized by using very high stirring speed. To iocate the minimum stirring speed at which the external mass transfer is negligible, several diffusional runs with different stirring speeds have been done. Figure 12 shows the dimensionless bath concentration with respect to time at different stirring speeds. From this Figure it can be seen that the external mass transfer resistance at stirring speed greater than $800 \mathrm{rpm}$ appears to be negligible.

Figures 13-16 also plot $t$ vs. $t$ for different stirring speeds. As shown in Figures 13 and 14 , the plots of $t^{*}$ vs. $t$ are 
not straight lines at the stirring speeds of 60 and $100 \mathrm{rpm}$, respectively. If the stirring speed is higher than $800 \mathrm{rpm}$, the plots of $t$ vs. $t$ are straight lines, as shown in Figures 16 and 17. Based on the theoretical analysis discussed before, we can conclude that the external mass transfer effect is negligible at stirring speed higher than $800 \mathrm{rpm}$. Thus we chose a stirring speed of $800 \mathrm{rpm}$ for the diffusional experiments.

\section{COMPARISON OF METAL AND GLASS CELLS}

In our diffusion experiments, a specific glass diffusion cell was also designed to perform diffusion experiments. The stirring of the glass diffusion cell was obtained by using a magnetic stirrer in which the catalyst was stationary and the bath solution was stirred. Figure 17 compared the diffusion kinetics in the metal cell at $800 \mathrm{rpm}$ stirring speed and in the glass cell with magnetic stirring. This Figure shows that the kinetics in the metal and the glass diffusion cells are nearly the same at the same diffusion conditions, which provide further evidence that the external mass transfer is negligible both in metal and glass diffusion cells.

\section{CONCLU8IONB}

Based on the above discussions, the following conclusions can be drawn:

1. In our diffusion experiments, the external mass transfer effects can be neglected both in the metal cell at $800 \mathrm{rpm}$ stirring speed and the magnetically stirred glass cell. 
2. The estimated particle surface concentration for the specific diffusion system is nearly the same as the finite bath concentration, which means that external mass transfer effect can be neglected.

3. Using experimental particle sizes of $R=0.018-0.08 \mathrm{~cm}$ at our diffusion conditions gives negligible external mass transfer effects. 


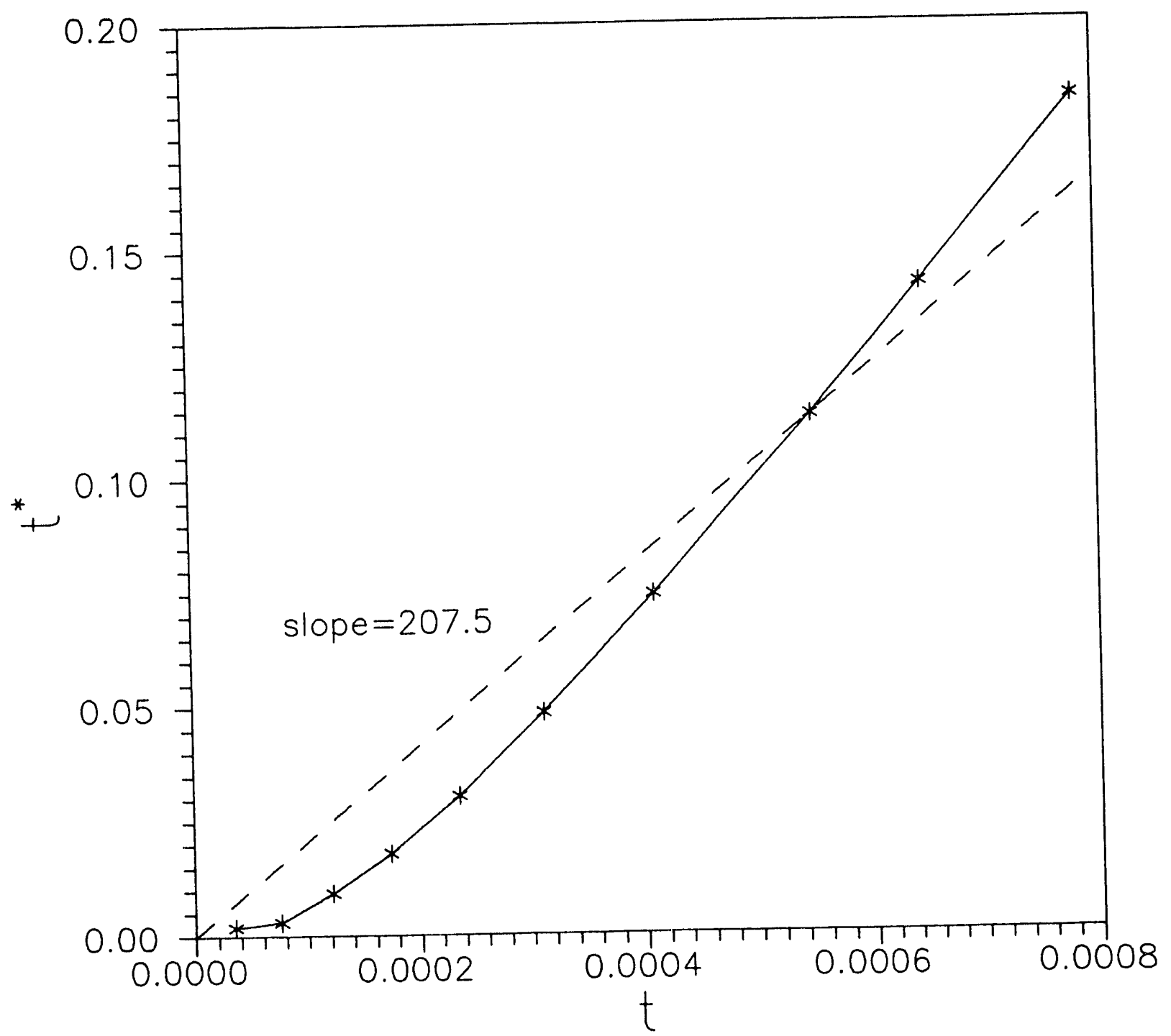

Fig. $1 \quad \mathrm{t}^{*} \quad$ vs. $\mathrm{t}$ at $\mathrm{L}=0.1$ 


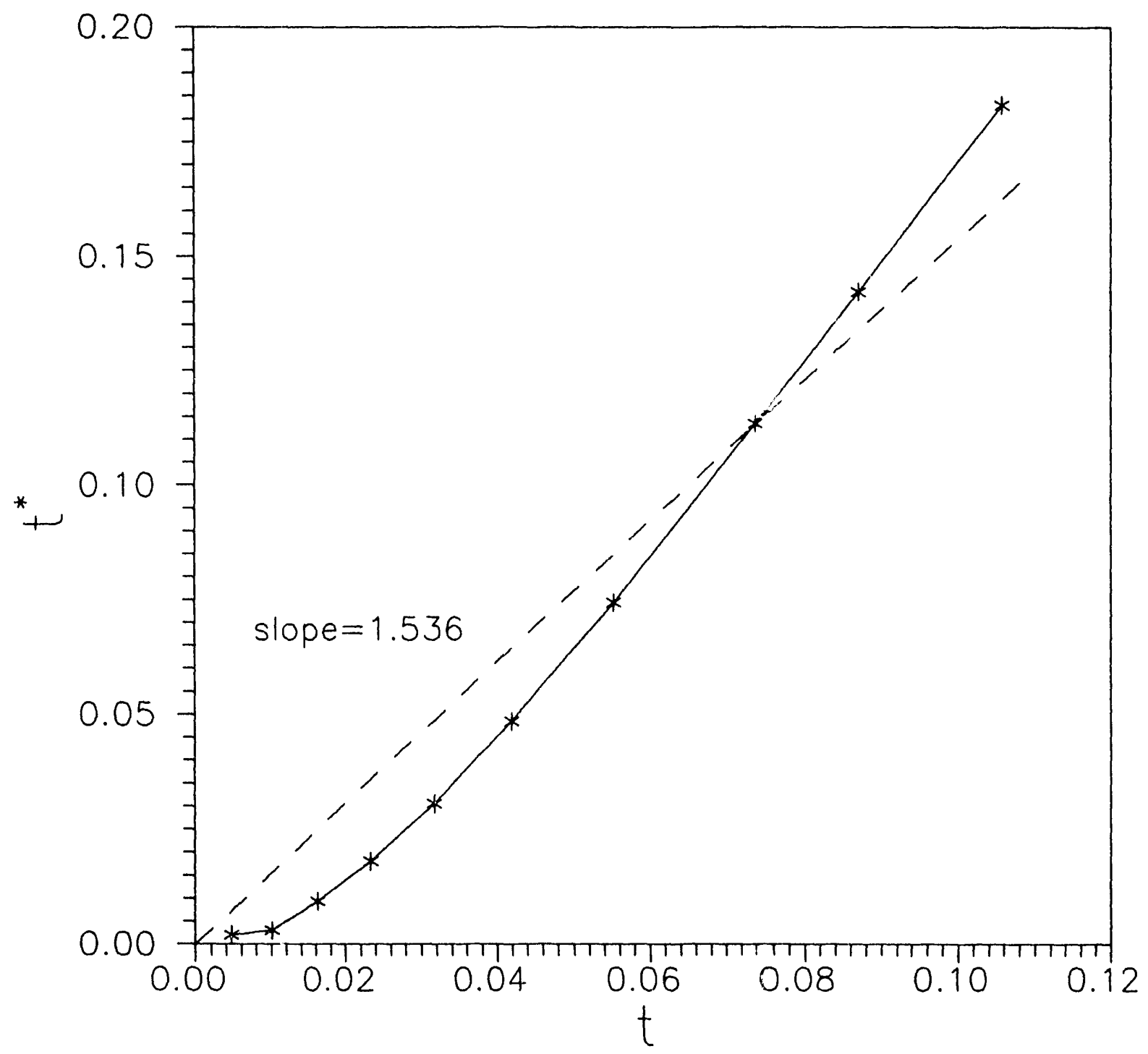

Fig. $2 t^{\circ}$ vs. $t$ at $\mathrm{L}=0.5$ 


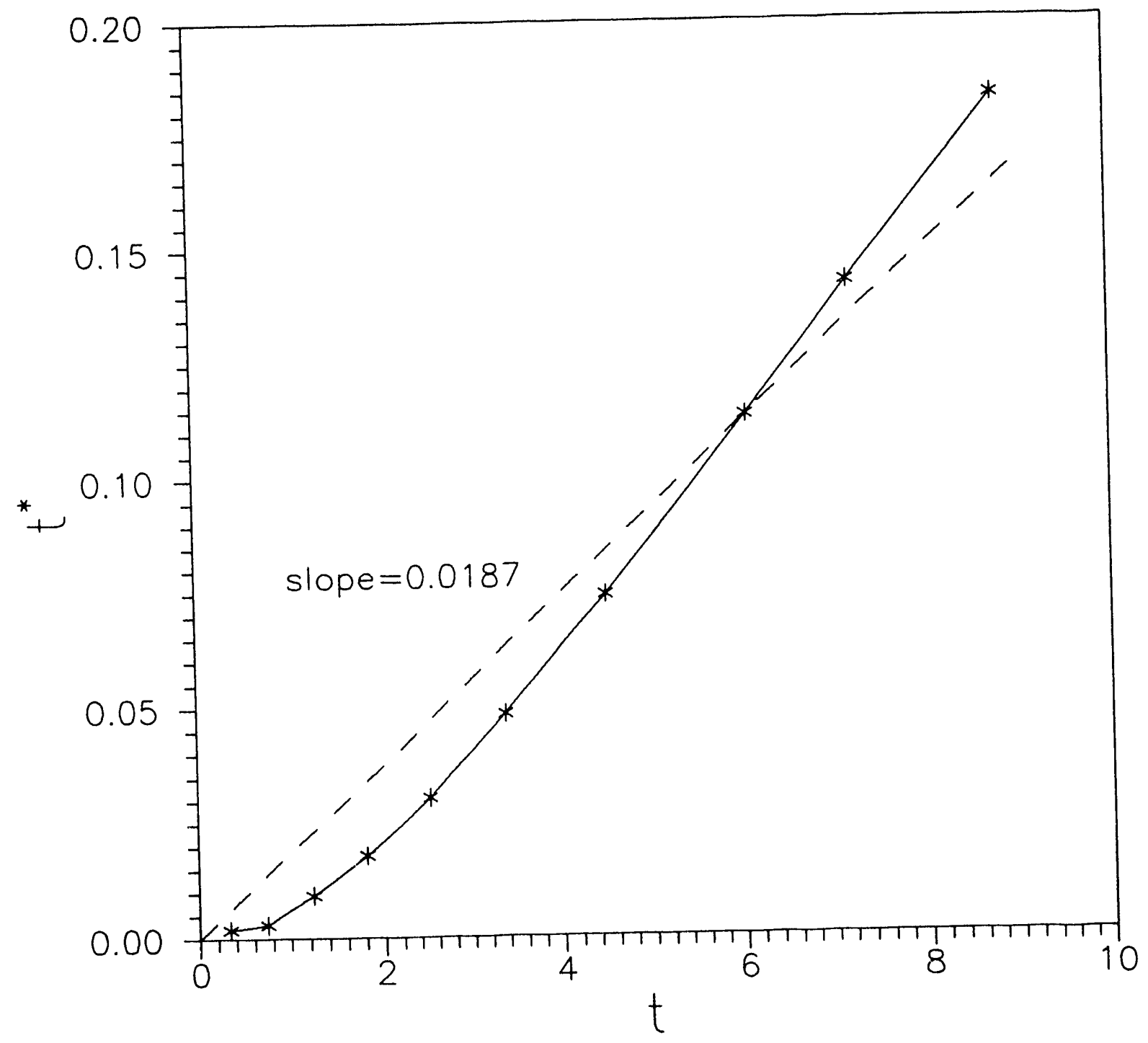

Fig. $3 \mathrm{t}^{\circ}$ vs. $\mathrm{t}$ at $\mathrm{L}=2.0$ 


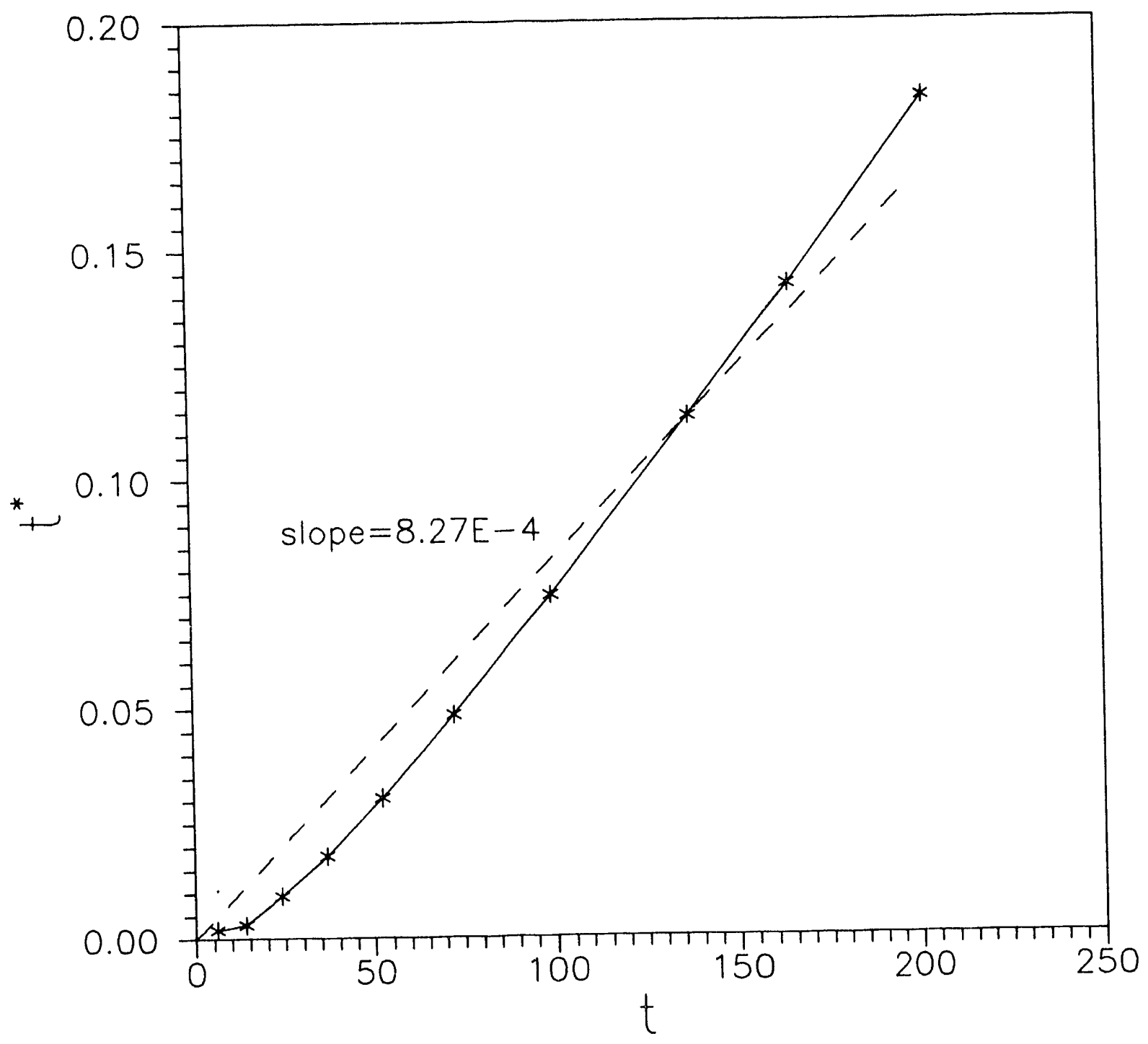

Fig. $4 \mathrm{t}^{*}$ vs. $\mathrm{t}$ at $\mathrm{L}=5.0$ 


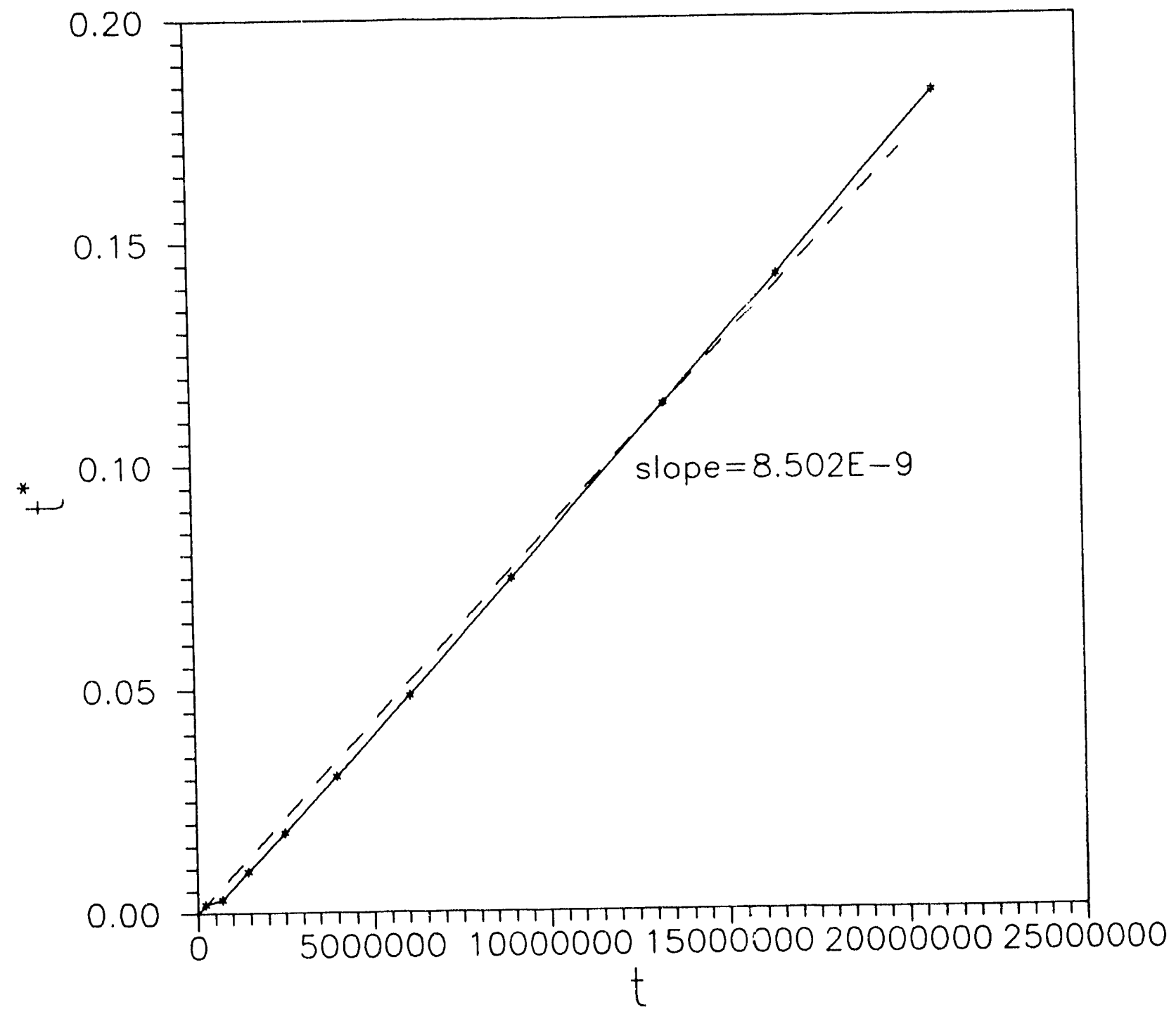

Fig. $5 t^{\circ}$ vs. $t$ at $L=100$ 


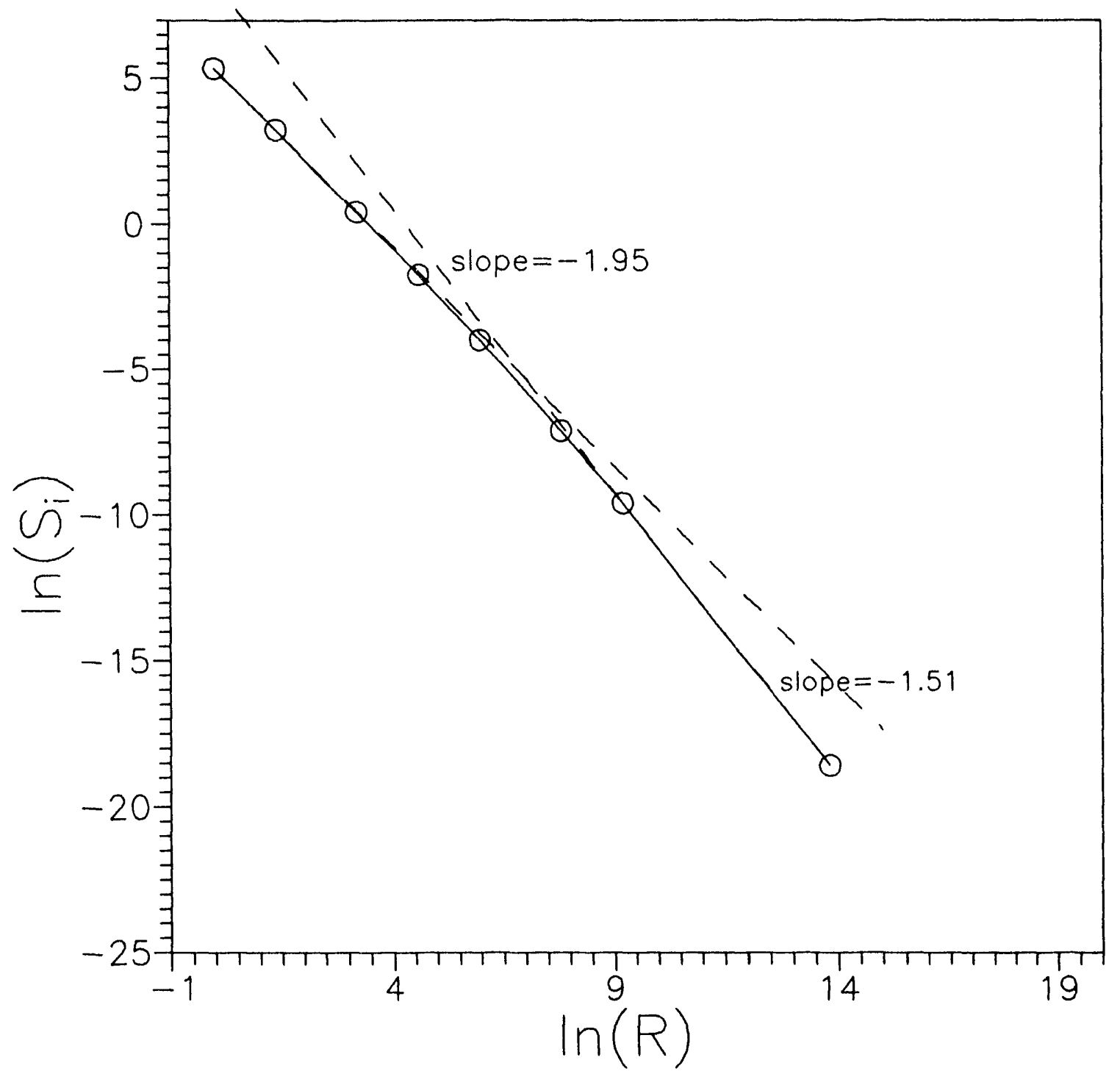

Fig. 6 Plot of $\ln (R)$ vs. $\ln \left(S_{i}\right)$ 


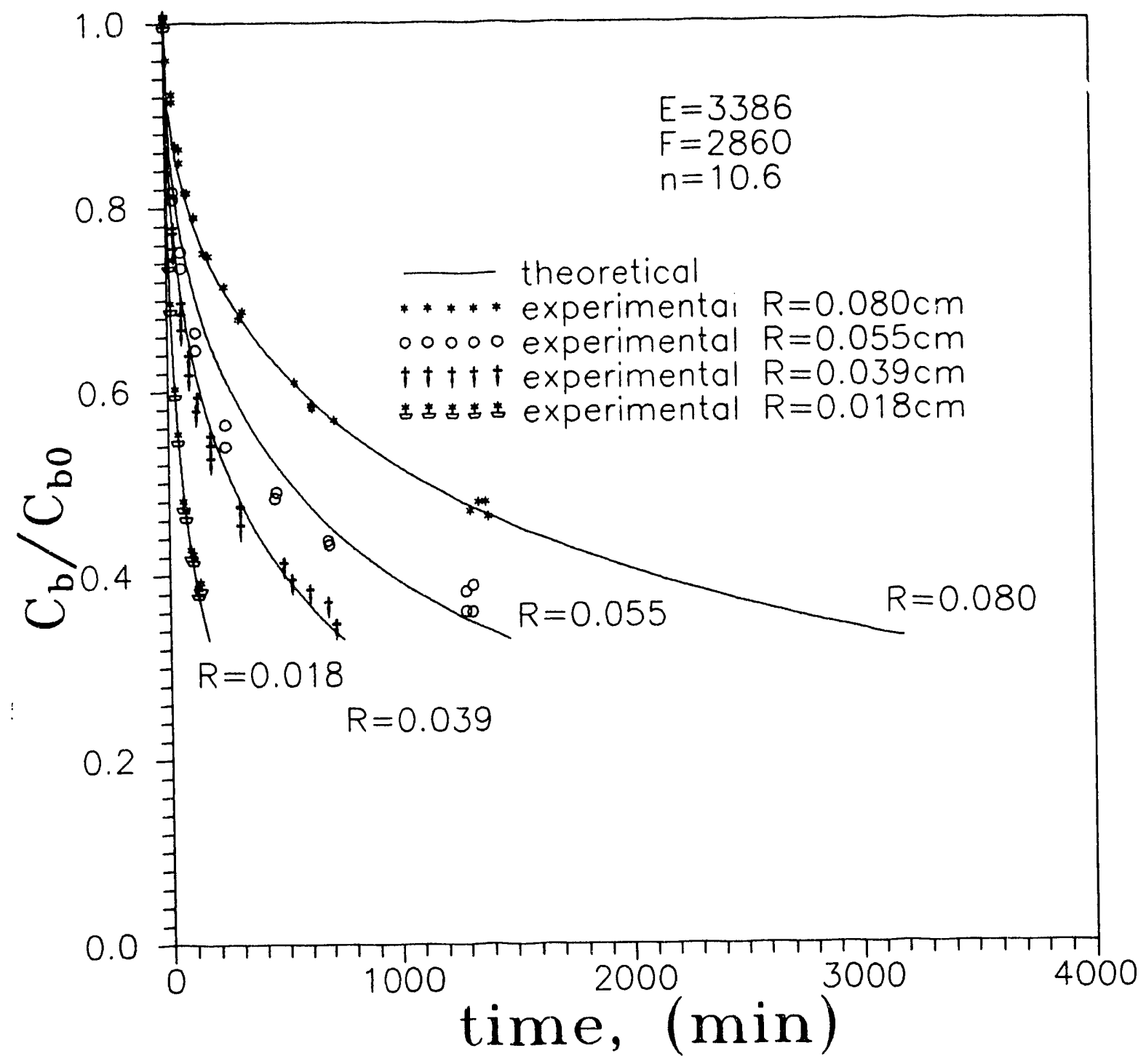

Fig. 7 Diffusion Kinetics of Quinoline in Cyclohexane with Shell 324 Catalysts with Four Particale Sizes, Stirring Speed 800 rpm 


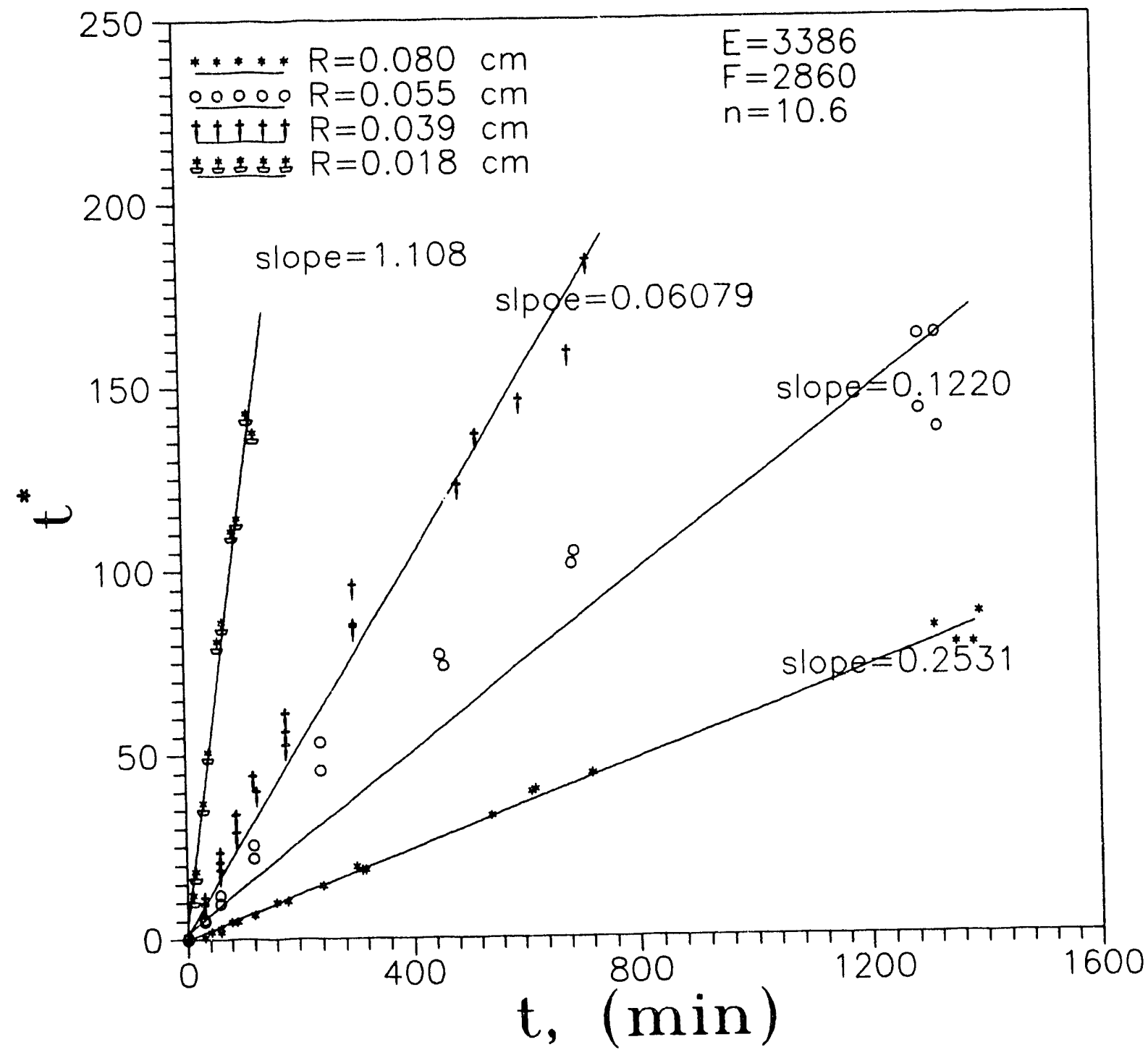

Fig. 8 Fit of Adsorptive Diffusion Rate Data to Pore Diffusion Model for Quinoline in Cyclohexane with Three Particale Size Shell 324 Catalyst, Stirring Speed 800 rpm 


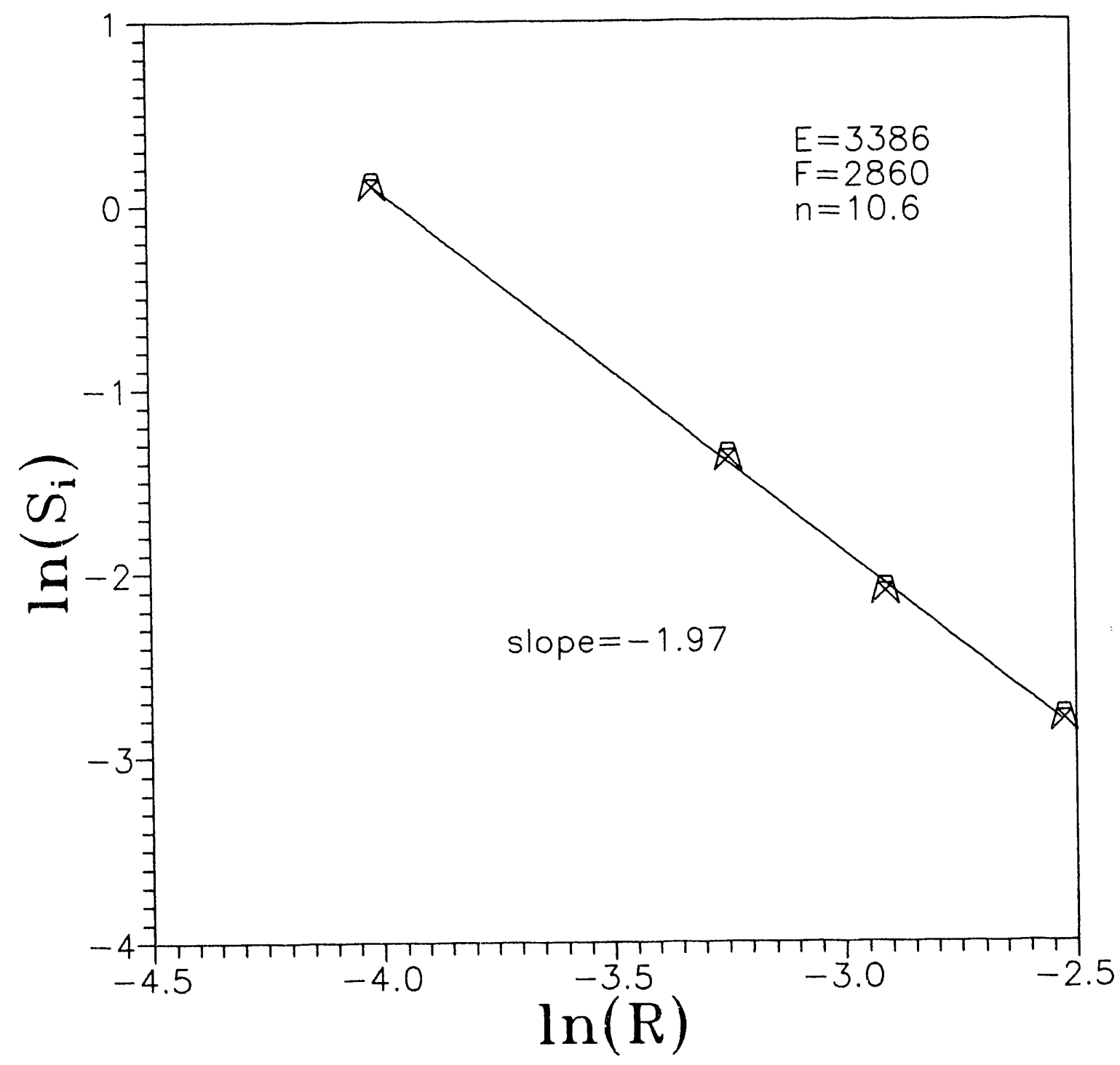

Fig. $9 \ln \left(S_{\mathrm{i}}\right)$ vs. $\ln (\mathrm{R})$ 


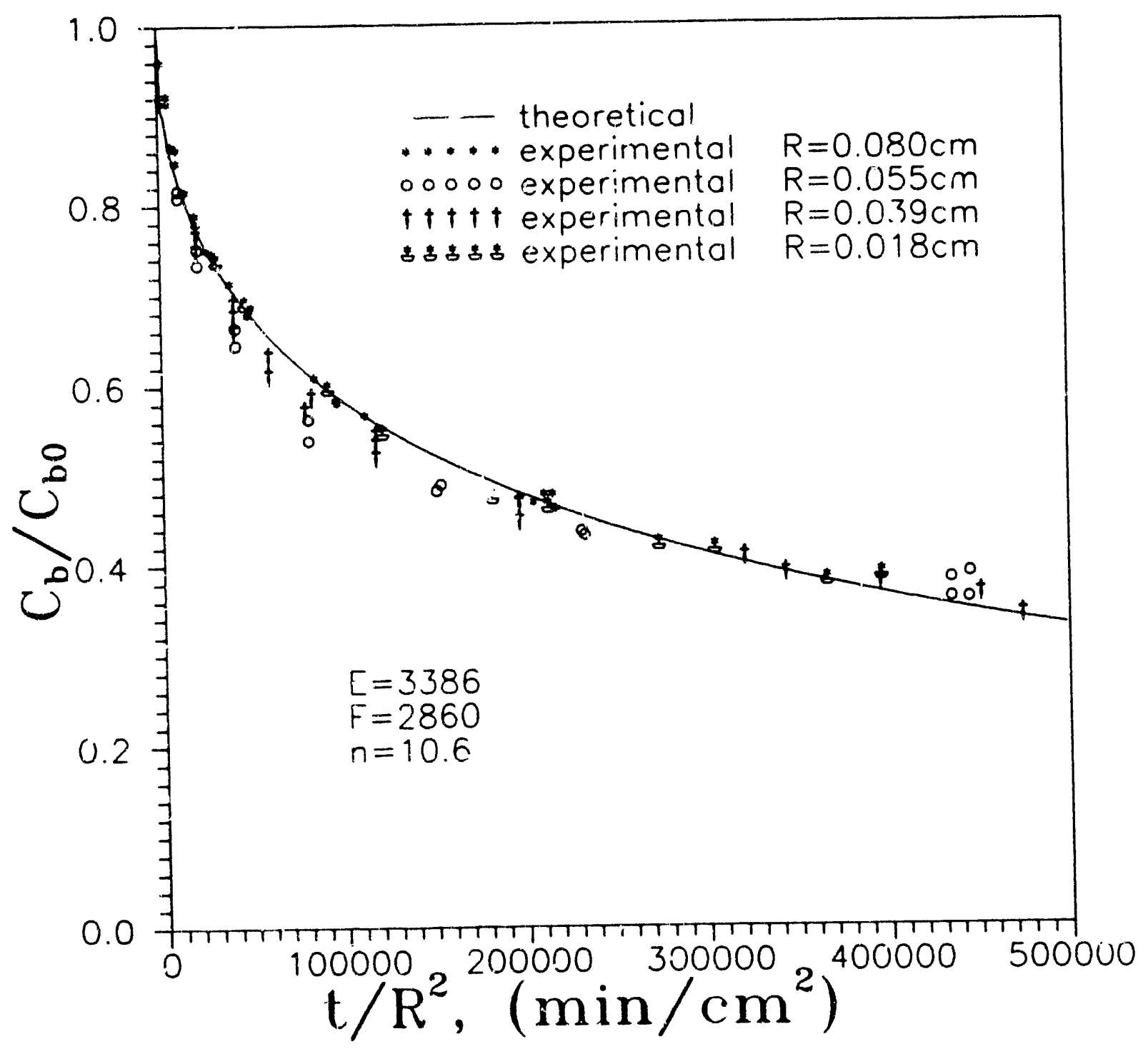

Fig. 10 Plot of $\mathrm{C}_{b} / \mathrm{C}_{\mathrm{b} 0}$ vs. $\mathrm{t} / \mathrm{R}^{2}$ for Four Particle Sizes 


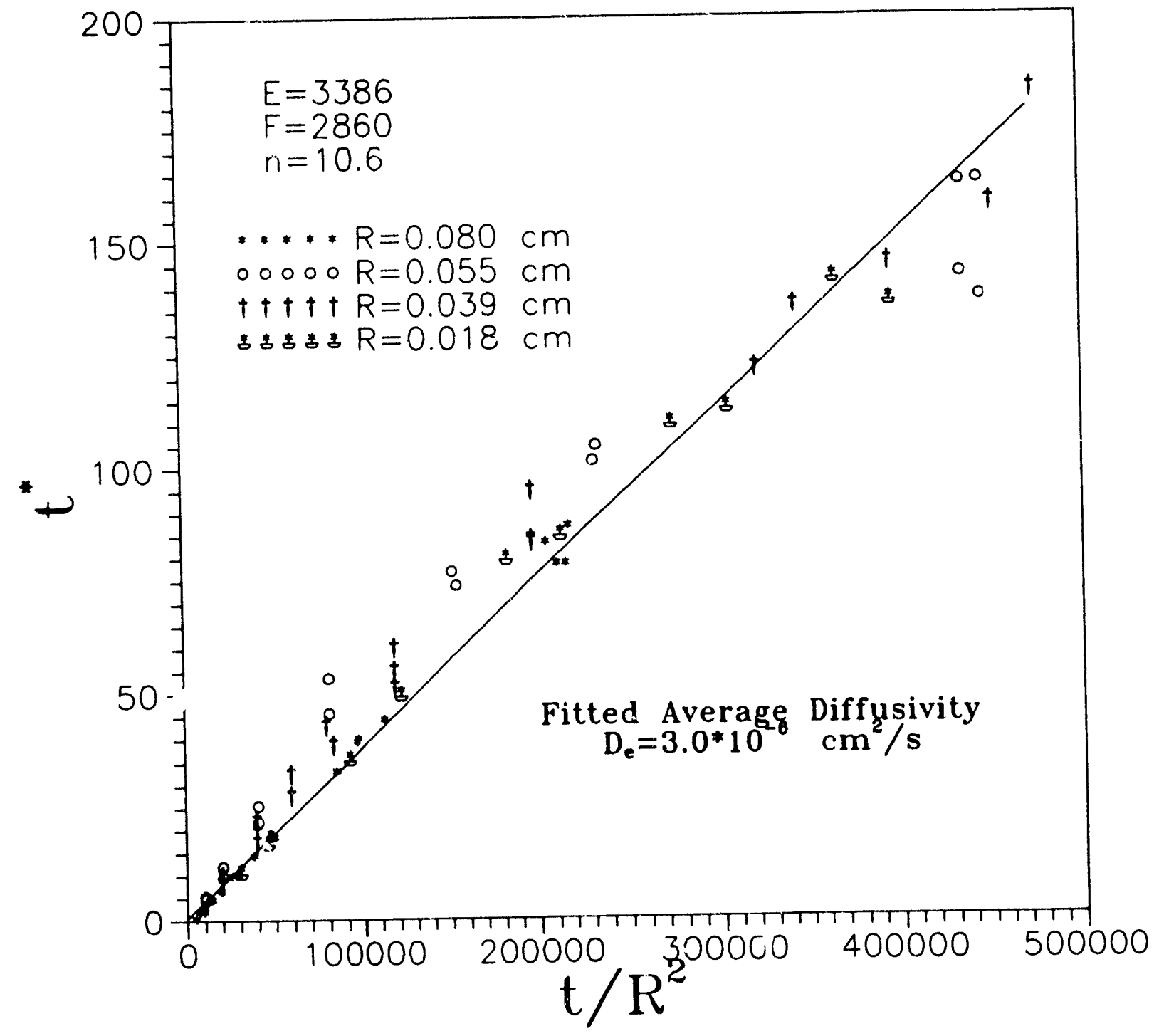

Fig. 11 Fit of Diffusion Rate Data to Pore Diffusion Model for Quinoline in Cyclohexane with Fresh Shell 324 


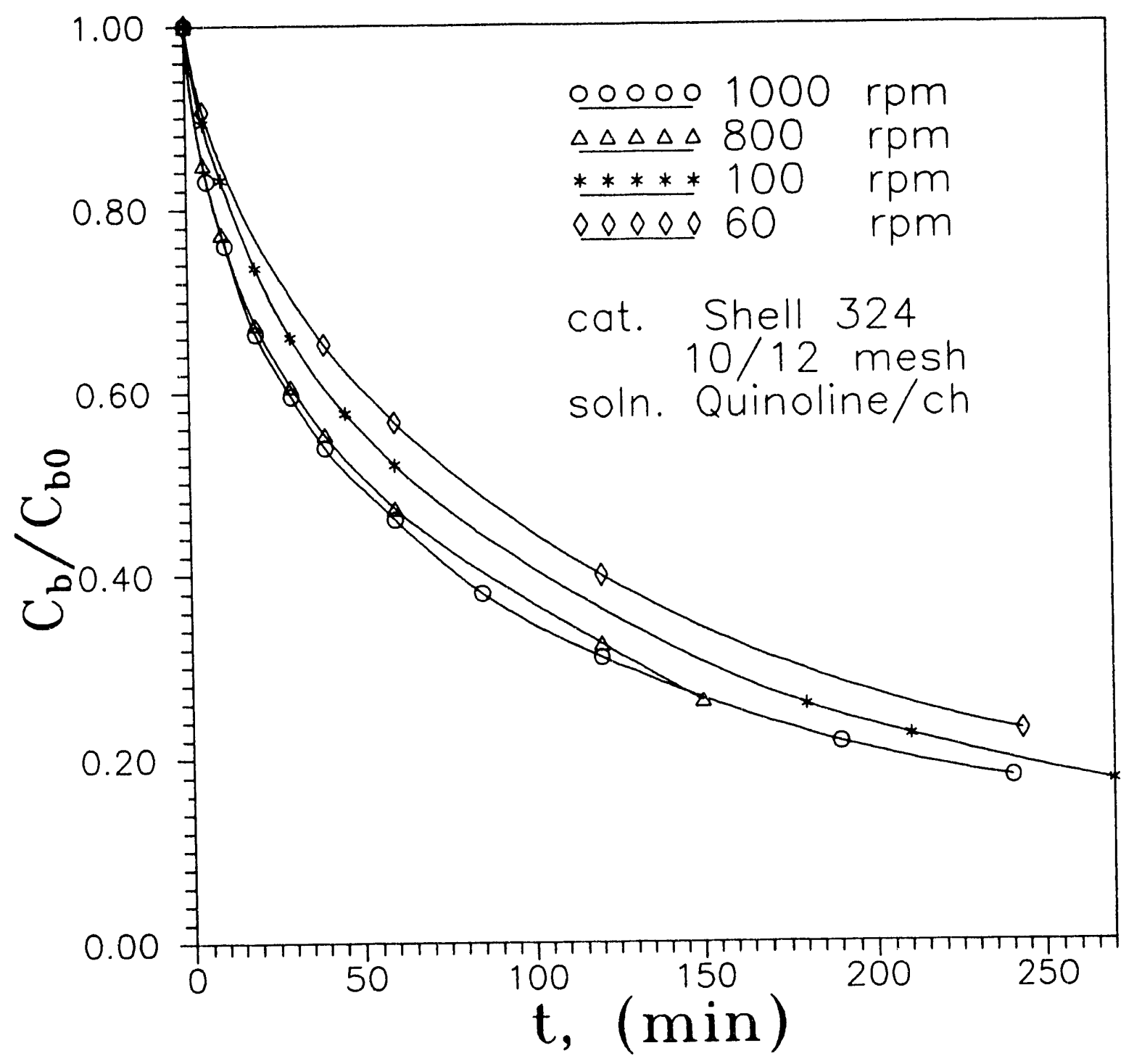

Fig. 12 Effect of Stirring Speed on the Diffusion Rate 


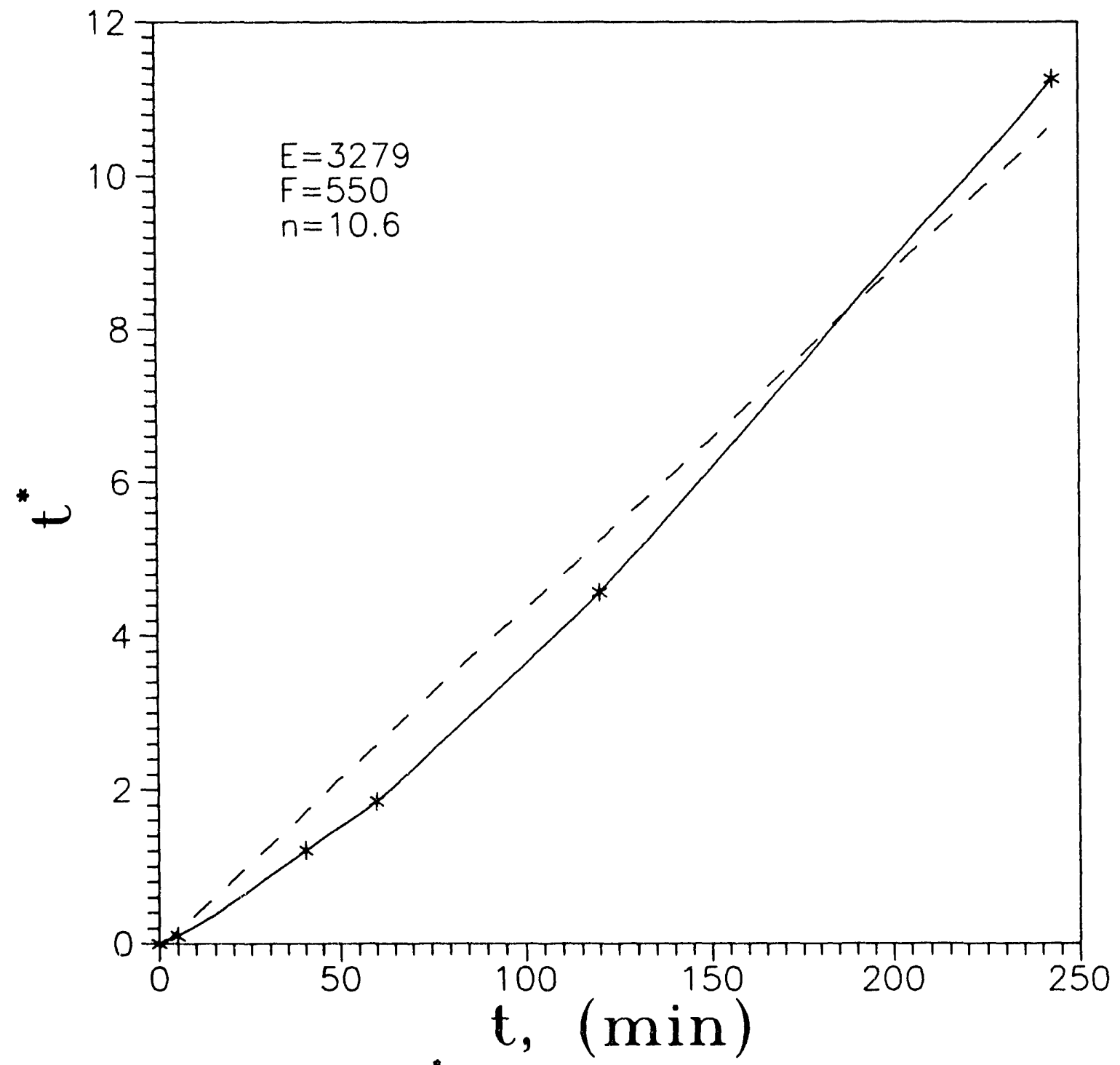

Fig. $13 \mathrm{t}^{*}$ vs. $t$ for Diffusion of Quinoline in Cyclohexane with Shell 324 at $60 \mathrm{rpm}$ Stirring Speed 


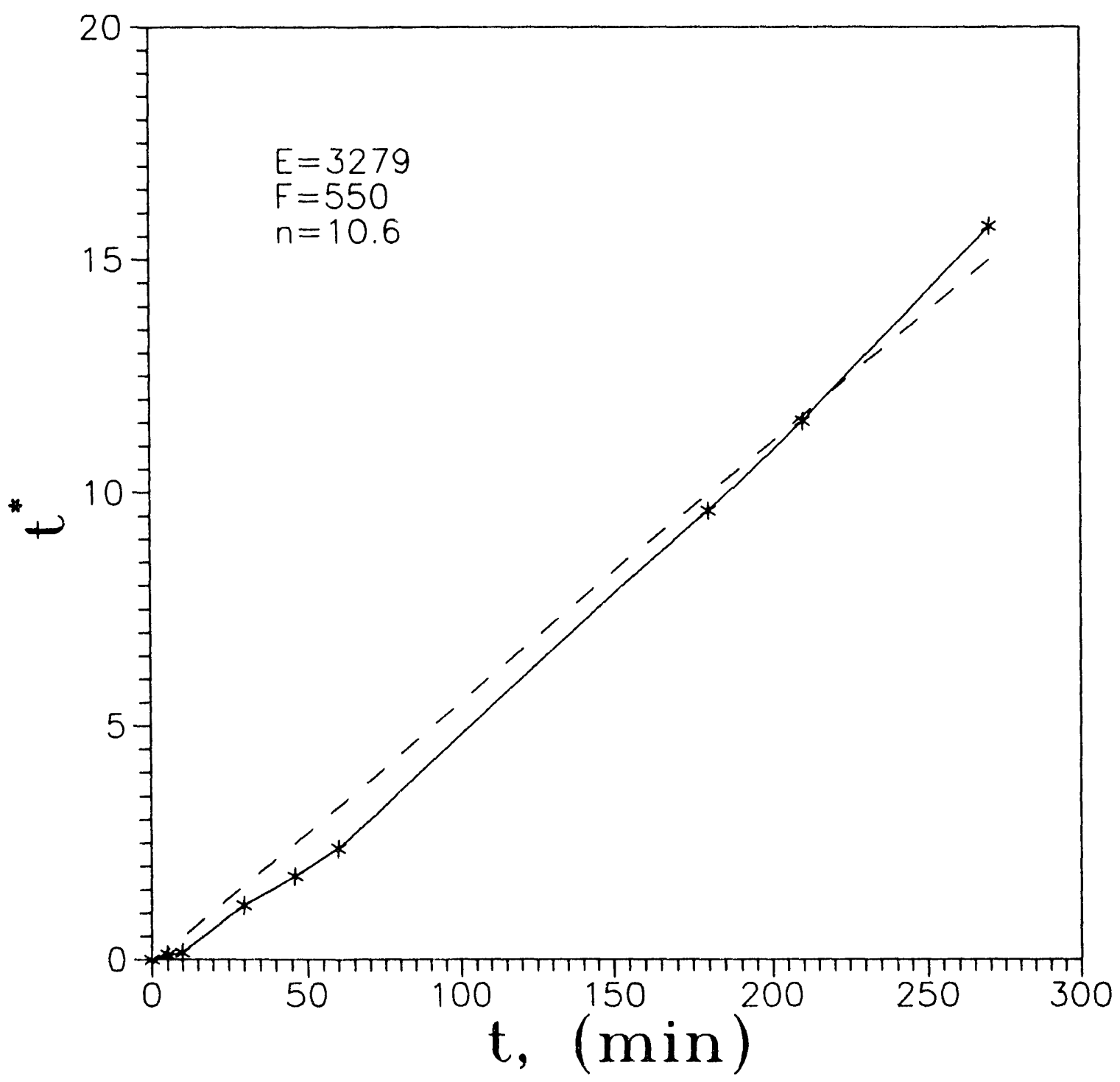

Fig. $14 t^{*}$ vs. $t$ for the Diffusion of Quinoline in Cyclohexane with Shell 324 a $t 100 \mathrm{rpm}$ Stirring Speed 


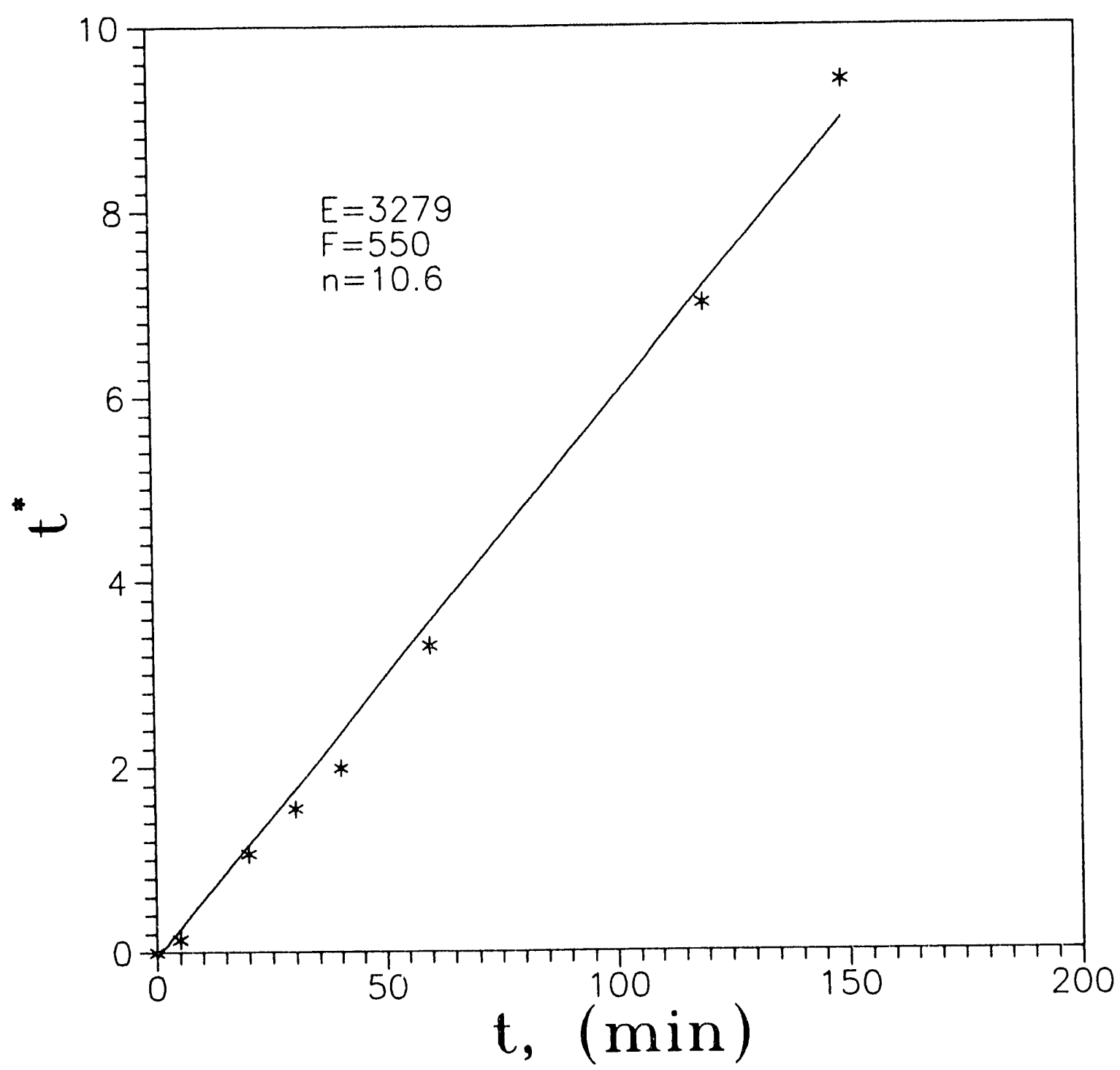

Fig. $15 t^{\circ}$ vs. $t$ for the Diffusion of Quinoline in Cyclohexane with Shell 324 at $800 \mathrm{rpm}$ Stirring Speed 


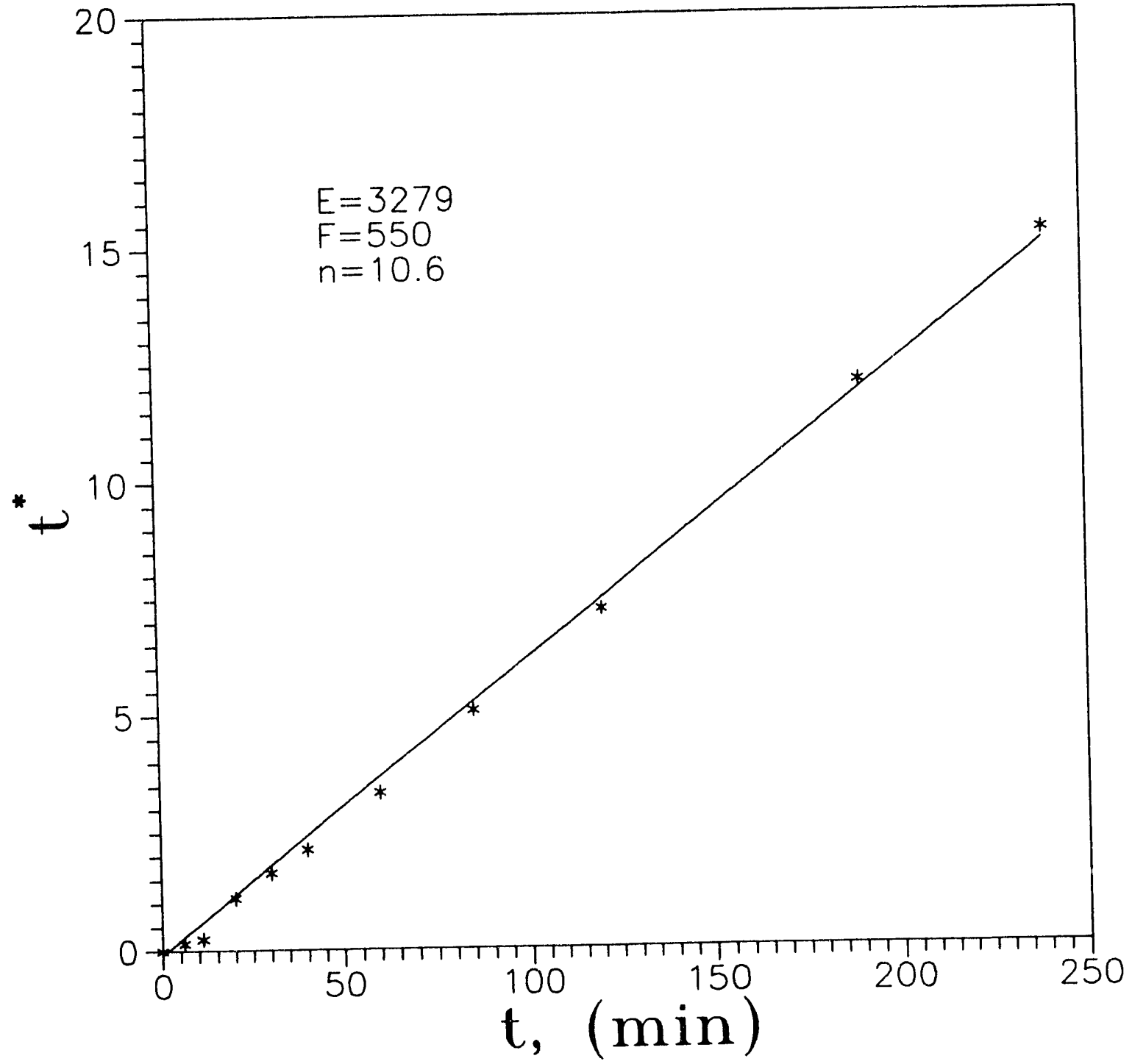

Fig. $16 t^{*}$ vs. $t$ for the Diffusion of $Q$ uinoline in Cyclohexane with Shell 324 at $1000 \mathrm{rpm}$ Stirring Speed 


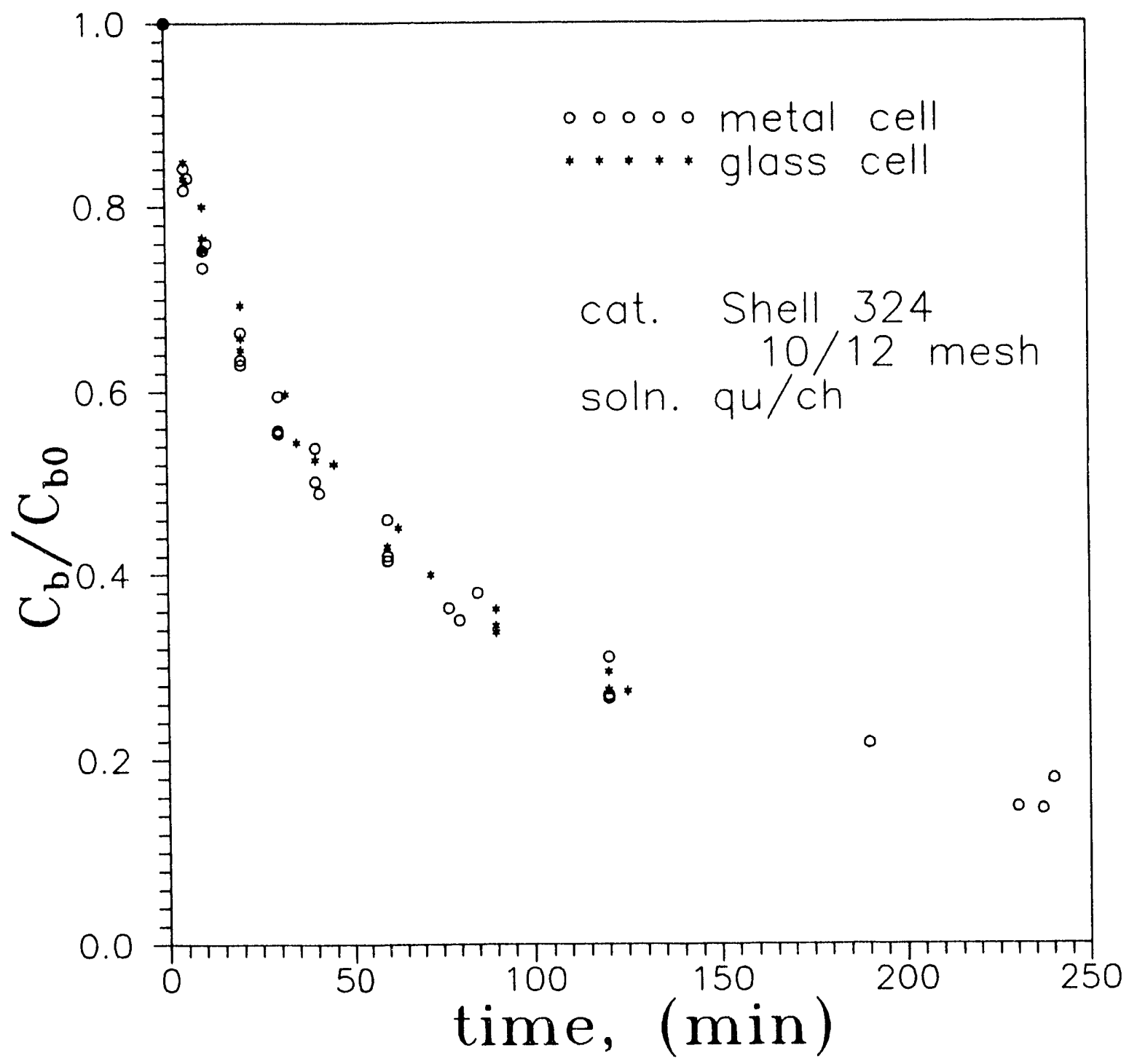

Fig. 17 Comparison of Diffusion

Data in Metal and Glass Cells 

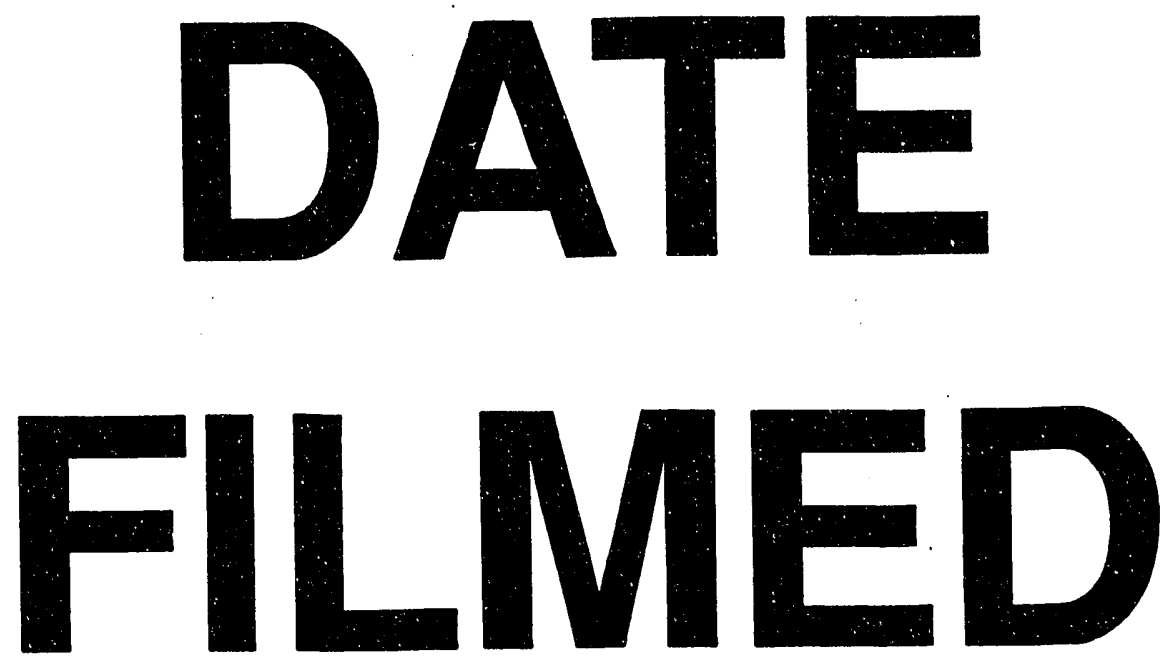

$8 / 18 / 93$
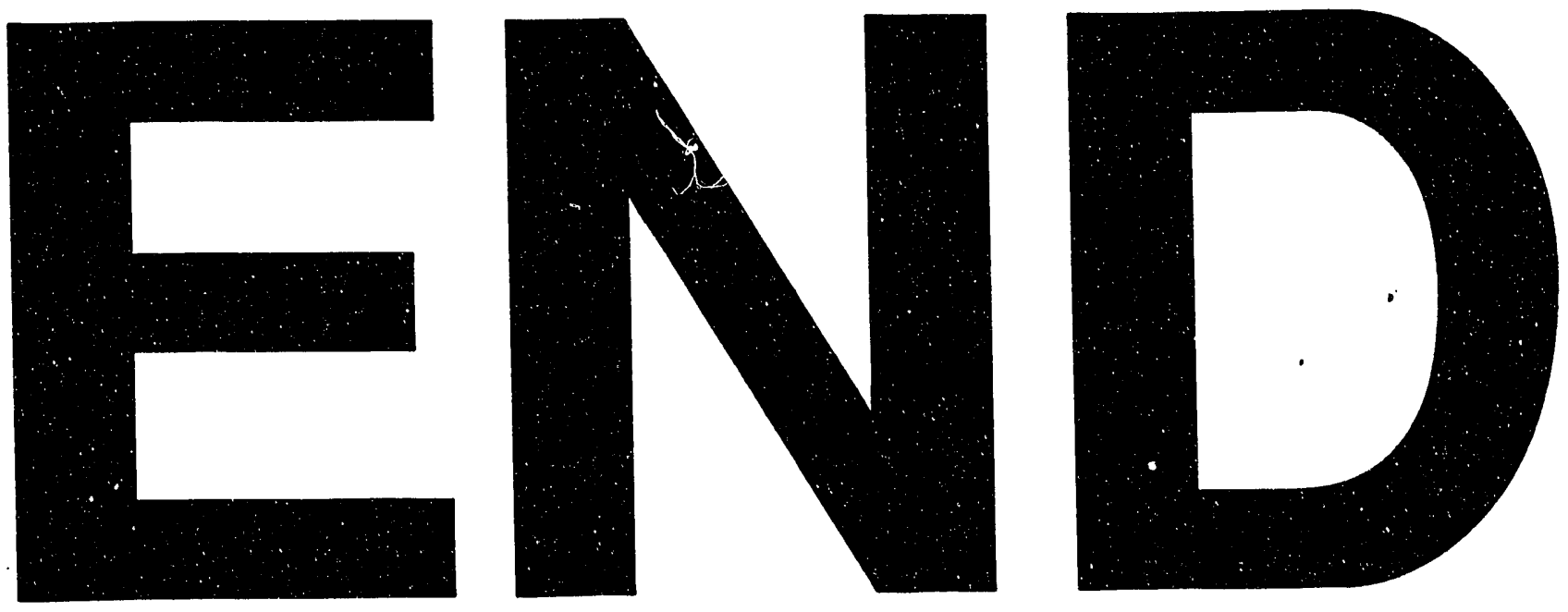
